\title{
What Are the Different Phenotypes of Inflammatory Bowel Disease in Asia?
}

\author{
Su Bee Park, Jin Young Yoon, and Jae Myung Cha \\ Department of Internal Medicine, Kyung Hee University Hospital at Gangdong, College of Medicine, Kyung Hee University, Seoul, \\ Korea
}

\author{
Article Info \\ Received August 20, 2021 \\ Revised November 16, 2021 \\ Accepted November 23, 2021 \\ Published online February 11, 2022 \\ Corresponding Author \\ Jae Myung Cha \\ ORCID https://orcid.org/0000-0001-9403-230X \\ E-mail drcha@khu.ac.kr
}

\begin{abstract}
The burden of inflammatory bowel disease (IBD) in Asia has been increasing over the past decades. Although patients with IBD show heterogenous phenotypes depending on the individual characteristics, no significant differences have been established in the IBD phenotypes of Western and Asian populations. However, despite the much lower incidence of IBD in Asia than in Western countries, the incidence has been rapidly increasing in Asia while remaining stable in Western countries. The incidence of ulcerative colitis (UC) showed an earlier and a more marked increase than the incidence of Crohn disease (CD), but the UC-to-CD ratio has recently decreased because of a relative increase in the incidence of $C D$ in Asia. While CD shows a significant male predominance, UC only shows a slight male predominance. A recent study reported that the incidence of IBD in Asia showed a bimodal age distribution with increasing IBD prevalence, similar to the findings of Western studies. CD in Asian patients, especially those in East Asia, is characterized by ileocolonic involvement and perianal fistula. The frequency of extraintestinal manifestations, including primary sclerosing cholangitis, appears to be lower in Asia, but this finding should be interpreted with caution due to the transient and nonspecific nature of these manifestations. Although familial aggregation is lower in East Asia, it may also be explained by the low prevalence of IBD in Asia. Thus, more studies should focus on the differences in phenotypes in Asian IBD patients versus Western patients. (Gut Liver 2022;16:676-685)
\end{abstract}

Key Words: Ulcerative colitis; Crohn disease; Inflammatory bowel disease; Phenotype; Asia

\section{INTRODUCTION}

Inflammatory bowel disease (IBD) is characterized by idiopathic chronic inflammation of the gastrointestinal tract, of which the two major forms are ulcerative colitis (UC) and Crohn's disease (CD). The burden of IBD is expected to increase exponentially because of the characteristics of this disease, that is, young age of onset, low mortality, and lack of a cure. ${ }^{1}$ Although IBD was traditionally considered as a disease of Western countries, mainly North America and Europe, ${ }^{2}$ the IBD disease burden has recently increased in many Asian countries. ${ }^{3-5}$ While the overall prevalence of IBD remains low in Asia, the prevalence has been steadily increasing in many Asian countries over the past two decades because of the urbanized, industrialized, and westernized lifestyles in Asia. ${ }^{1}$ However, even with the low prevalence of IBD in Asia, the absolute number of IBD patients in Asia is expected to be greater than those in Western countries because of the larger population size of approximately 4.68 billion people in Asia (about $60 \%$ of the total global population), in comparison with the 0.6 billion people in North America and the 0.75 billion people in Europe. Although patients with IBD show heterogenous phenotypes according to individual characteristics, no significant differences have been established in the IBD phenotypes between the Western and Asian populations. Nevertheless, several studies have reported that some demographic and phenotypic characteristics of IBD at diagnosis in Asian countries differed from those in Western countries. A better understanding of the differences in the epidemiology of IBD between Asian and Western countries may provide important clues to the unknown aspects 
of the etiology and mechanism of IBD, thereby facilitating the management of IBD patients.

With this perspective, the present review focused on the demographic and phenotypic characteristics of IBD at the time of diagnosis in Asia, especially from the perspective of Korean IBD patients, in comparison with the corresponding findings in Western countries.

\section{INCIDENCE OF IBD}

The Asia-Pacific Crohn's and Colitis Epidemiologic Study (ACCESS), ${ }^{4}$ a population-based inception cohort covering eight Asian regions and Australia, reported that the crude overall incidences of IBD, UC, and CD were $1.37,0.76$, and 0.54 per 100,000 persons, respectively (Supplementary Table 1). In this study, the incidence of IBD was the highest $(3.4 / 100,000)$ in mainland China (Guangzhou), followed by 3.1/100,000 in Hong Kong and 2.2/100,000 in Macau. In Hong Kong, the incidence of IBD tripled from 1.0/100,000 to 3.1/100,000 over the last two decades. ${ }^{4}$ An extension study of ACCESS, which covered 13 countries or regions in Asia, updated the crude overall incidences of IBD, UC, and CD to $1.14,0.76$, and 0.35 per 100,000 persons, respectively, between 2011 and 2012 and $1.89,1.20$, and 0.66 per 100,000 persons, respectively, between 2012 and 2013. ${ }^{5}$ A population-based study from Korea showed that the incidence of IBD has been increasing over the past three decades. ${ }^{6}$ In Korea, the adjusted incidence of UC increased 20.1-fold from $0.29 / 100,000$ to 5.82/100,000 during 1986-2015, and adjusted incidence of CD increased 40.7-fold from $0.06 / 100,000$ to $2.44 / 100,000$ during the same period. ${ }^{6}$ The incidence of UC and CD began to increase in the late 1980s and late 1990s, respectively, in Korea. A population-based study from Wuhan, China in 2010, showed that the adjusted incidence rates of UC and CD were 1.45/100,000 and 0.51/100,000, respectively. ${ }^{7}$ Another population-based study from Zhongshan, China, during 2011-2012 also reported that the adjusted incidence rates of UC and CD were 2.05/100,000 and 1.09/100,000, respectively. ${ }^{8}$ The pooled incidence of UC in China tripled over the past 10 years, ${ }^{9}$ while nationwide data from Taiwan reported an increasing incidence of IBD from 1998. ${ }^{10,11}$ The crude incidence of UC increased 1.8fold from $0.54 / 100,000$ to $0.95 / 100,000$ during $2001-2015$ and that of $\mathrm{CD}$ also increased 2.8-fold from $0.17 / 100,000$ to $0.47 / 100,000$ during the same period, respectively. ${ }^{12}$ In Lebanon, the mean incidence rates of UC and CD were $4.1 / 100,000$ and 1.4/100,000 person-years, respectively, ${ }^{13}$ while the incidence rates of UC in Kuwait and Israel were $2.8 / 100,000$ and 5.0/100,000, respectively. ${ }^{14,15}$
The incidence of IBD in Asia is much lower than those in Western countries, where the highest annual incidence rates of UC and CD were 24.3/100,000 and 12.7/100,000 person-years in Europe and 19.2/100,000 and 20.2/100,000 in North America, respectively. ${ }^{2}$ However, while the incidence of IBD is high but stable in Western countries, it is low but rapidly increasing in Asian countries. ${ }^{3,6}$ Moreover, the incidence of IBD varies within and between Asian countries, indicating the need for more population-based studies from Asia.

\section{PREVALENCE OF IBD}

In Korea, the overall age- and sex-adjusted prevalence rate of IBD was 76.66/100,000 for UC and 31.59/100,000 for CD on December 31, 2015 (Table 1). ${ }^{6}$ In Japan, the estimated annual prevalence rate of IBD was 172.9/100,000 for UC and 55.6/100,000 for CD on a mail-based survey targeting hospitals in $2014 .{ }^{16}$ It was limited data as it was based on mail-based survey using a stratified random sampling method. In Taiwan, the mean annual prevalence was 4.59/100,000 for UC and 1.05/100,000 for CD during 1998$2010 .{ }^{11}$ In a cross-sectional study from Kazakhstan, the adjusted prevalences of IBD, UC, and CD were 113.9/100,000, $84.4 / 100,000$, and $29.5 / 100,000$, respectively. ${ }^{17}$ In Western Asia, the prevalence of IBD in Turkey ${ }^{18}$ and Israel ${ }^{15}$ was $4.9 / 100,000$ and $167.2 / 100,000$, respectively. In a global review, the highest prevalence of IBD was 505/100,000 for UC and 322/100,000 for CD in Europe and 249/100,000 for UC and 319/100,000 for CD in North America, which were much higher than the prevalences of 168/100,000 for UC and 68/100,000 for CD in Asia and the Middle East. ${ }^{2}$ Although the prevalence of IBD in Asia is lower than those in Western countries, the prevalence has been continuously increasing in many Asian countries. ${ }^{19-21}$ In Korea, the prevalence of UC increased 4.1-fold from 7.57/100,000 to $30.87 / 100,000$ during $1997-2005 .{ }^{19}$ In Japan, the prevalence of CD increased 4.6-fold from 2.9/100,000 to 13.5/100,000 during 1986-1998. ${ }^{20}$ In Singapore, the prevalence of CD increased 5.5-fold from 1.3/100,000 to 7.2/100,000 during 1992-2004. ${ }^{21}$ In Taiwan, the prevalence of UC increased 6.1-fold from 2.1/100,000 to $12.8 / 100,000$ during 20012015 , and the prevalence of CD also increased 6.5-fold from $0.6 / 100,000$ to $3.9 / 100,000$ during the same period. ${ }^{12}$ In Hong Kong, the prevalence of UC increased 2.8-fold from $2.26 / 100,000$ to $6.30 / 100,000$ during $1997-2006 .{ }^{22}$ In Israel, the prevalence of IBD increased from 121/100,000 to 167.2/100,000 during 1987-1997. ${ }^{15}$

The increasing prevalence of IBD in Asia may reflect an actual increase in the population with IBD, increased 
Table 1. Summary of Different Phenotypes of Inflammatory Bowel Disease in the Asian and Western Population

\begin{tabular}{|c|c|c|}
\hline Different phenotype & Asia & West \\
\hline Incidence of IBD & Still low, but rapidly increasing. & High, but stable. \\
\hline Prevalence of IBD & $\begin{array}{l}\text { Rapidly increasing and their gap between Asia and } \\
\text { West is narrowing. }\end{array}$ & Much higher. \\
\hline \multicolumn{3}{|l|}{ Environmental and dietary factors } \\
\hline Brest feeding, physical activity & \multicolumn{2}{|c|}{ Both protective effect on IBD development in Asia and West. } \\
\hline Smoking & No association for the risk of $C D$. & Increased risk of CD. \\
\hline Appendectomy & $\begin{array}{l}\text { Inconsistent effect on the risk of UC (no association }{ }^{23} \\
\text { vs decreased risk }{ }^{24-26} \text { ). }\end{array}$ & Decreased risk of UC. \\
\hline Diet & $\begin{array}{l}\text { Sugar, fat, meat, oil has increased risk of IBD. But, } \\
\text { lower fiber has no association with the risk of IBD. } \\
\text { Daily tea and coffee have decreased risk of IBD. }\end{array}$ & $\begin{array}{l}\text { Sugar, fast food, red meat has increased risk of } \\
\text { IBD, and lower fiber has increased risk of IBD. }\end{array}$ \\
\hline $\mathrm{UC} / \mathrm{CD}$ ratio & $U C / C D$ ratio is high, but has been reduced. & $\mathrm{UC} / \mathrm{CD}$ ratio is low. \\
\hline Sex & $\begin{array}{l}\text { Male predominance in both } C D \text { and } U C \text {, but it is sig- } \\
\text { nificantly higher for } C D \text { and slightly higher for } U C \text {. }\end{array}$ & $\begin{array}{l}\text { Female predominance for } \mathrm{CD} \text {. } \\
\text { No sex predominance for UC. }\end{array}$ \\
\hline Age & $\begin{array}{l}\text { Bimodal age distribution is noted in recent studies, } \\
\text { but single peak is noted in the past studies. }\end{array}$ & Bimodal age distribution. \\
\hline \multicolumn{3}{|c|}{ Age at diagnosis is $5-10$ years earlier for $C D$ than that of $U C$ in Asia and West. } \\
\hline Disease extent of UC & \multicolumn{2}{|c|}{ No significant difference for the disease extent of UC between Asia and West. } \\
\hline Disease location of CD & $\begin{array}{l}\text { More } L 3 \text { location and higher proportion of } L 4 \text { for the } \\
\text { disease location of } C D \text {. }\end{array}$ & More L2 location for the disease location of CD. \\
\hline Disease behavior of CD & $\begin{array}{l}\text { Disease behavior is more complicated with more } \\
\text { perianal fistulas. }\end{array}$ & $70 \%-80 \%$ of $\mathrm{CD}$ has $\mathrm{B} 1$ behavior. \\
\hline Extraintestinal manifestation & Variable, but lower than those in West. & Variable. \\
\hline Family aggregation & Lower frequency. & Higher frequency. \\
\hline
\end{tabular}

IBD, inflammatory bowel disease; CD, Crohn disease; UC, ulcerative colitis.

awareness of this condition among physicians, and the improved healthcare utilization and diagnostic methods for IBD. Thus, the IBD burden in Asian countries is expected to be a major threat to global public health.

\section{ENVIRONMENTAL AND DIETARY FACTORS}

The evolution of IBD in many Asian countries appears to associate with recent changes of environmental and dietary factors, which may affect the intestinal microbiota and develop IBD in genetically susceptible patients. ${ }^{27}$ Brest feeding and physical activity exerts same protective effect for the IBD development in the Asian population as well as Western population. ${ }^{23,28,29}$ Breast feeding, which may influence the intestinal microbiota, showed a protective effect against IBD development in Asian population than Western population. ${ }^{28}$ Physical activity also had a protective effect against $\mathrm{CD}$ development in Asian and Western population. ${ }^{23,29}$ Active smoking is associated with an increased risk of $\mathrm{CD}$, and appendectomy is associated with a decreased risk of UC in the Western population. ${ }^{30}$ Active smoking was not significantly associated with development of $\mathrm{CD}$ in a recent Japanese case-control study (odds ratio [OR], 1.82; $95 \%$ confidence interval [CI], 0.85 to 3.92$)^{31}$ Cigarette smoking is not associated with the development of $\mathrm{CD}$ in a single-center Korean study, either. ${ }^{32}$ In the ACCESS cohort, appendectomy was not associated with the risk of UC in the Asian population (OR, 0.437; 95\% CI, 0.129 to 1.474 ) as well as in the Australian population. ${ }^{23}$ However, appendectomy was protective against UC in other Asian studies from Japan, ${ }^{24}$ China, ${ }^{25}$ and Iran ${ }^{26}$ like Western studies. The role appendectomy for the risk of UC should be further evaluated for the age and indication (appendicitis vs lymphadenitis) of appendectomy as their role remains inconsistent in Asian population.

Western diet, particularly increased consumption of sugar, fast food, fatty acids, red meat as well as decreased consumption of dietary fiber, has been suspected to develop IBD, ${ }^{33}$ as they can change intestinal microbiota. While, increased consumption of fiber, fruit, and vegetable reduced the risk of IBD development. ${ }^{34}$ In the ACCESS cohort, however, no association was found between consumption of fiber, fruits or vegetables and the risk of development of IBD in Asia. ${ }^{23}$ In this cohort, the consumption of tea and coffee which may contain antioxidants was associated with the lower risk of IBD development. ${ }^{23}$ Two Japanese studies ${ }^{35,36}$ also reported that consumption of sugar, fat, fatty acids, meat and oil increased the risk of IBD development, which were consistent findings with Western studies. Dietary studies need to be interpreted with caution as many of dietary studies are difficult to classify and inter- 
pret complex dietary data. However, it is important to keep in mind that environmental and dietary factors may have different effect in the Asian population compared with the Western population, and future studies should be focused on these issues. It is important to increase our insight into the role of environmental and dietary factors for the development of IBD in Asian population to prevent the surge of the Asian IBD.

\section{UC AND CD RATIO}

In the ACCESS study, the incidence and prevalence of UC were about twice those of $\mathrm{CD}$ in the included eight Asian countries. ${ }^{4}$ The extension study of ACCESS also reported a UC/CD ratio of 1.9 in 13 Asian countries or regions. ${ }^{5}$ In Korea, the UC/CD ratio was 2.4 during 2011-2015. ${ }^{6}$ In two Chinese studies, the UC/CD ratios were 2.8 in $2010^{6}$ and 1.9 during $2011-2012 .{ }^{8}$ In Japan, the $\mathrm{UC} / \mathrm{CD}$ ratio was 3.11 on a nationwide survey. ${ }^{16}$ In India ${ }^{37}$ and Iran, ${ }^{38}$ the UC/CD ratio was 1.4 and 2.2 , respectively. Another study from India reported a high UC/CD ratio of 5.1. ${ }^{39}$ Overall, the incidence of UC is about twice that of $\mathrm{CD}$ in Asian countries, ${ }^{2-7,37,38}$ indicating that the number of UC patients grew much faster than that of CD in Asian countries, which is similar to the trend in Western countries. $^{40}$

Recently, however, the UC/CD ratio in many Asian countries has reduced because of the accelerating incidence of CD. ${ }^{6,12}$ In Korea, the UC/CD ratio was 4.8 in 1986-1990, but it reduced to 2.4 in 2011-2015. ${ }^{6}$ In Taiwan, the UC/CD ratio was 4.3 in 2001-2005, but it similarly decreased to 2.03 in 2011-2015. ${ }^{12}$ In the Australia data of the ACCESS cohort, $\mathrm{UC} / \mathrm{CD}$ ratio was even reversed as $0.51^{4}$ and $0.6{ }^{5}$ which means the incidence of $\mathrm{CD}$ excessed those of $\mathrm{UC}$ in Australia.

\section{SEX}

A recent systematic review of studies from 11 Asian countries reported that the male-to-female $(\mathrm{M} / \mathrm{F})$ ratio of IBD at diagnosis was 1.2 to 1.4 for UC and 1.4 to 1.6 for $\mathrm{CD} .^{41}$ This study found a marked male predominance in both $\mathrm{CD}$ and UC incidence, which started in adolescence and extended past middle age to 50 years of age in $\mathrm{CD}$ or 65 years of age in UC. ${ }^{41}$ In Korea, the M/F ratio of the adjusted incidence rate was 1.2 for UC and 3.3 for $\mathrm{CD}^{6}{ }^{6}$ Similarly, in most East Asian countries, including Korea, Japan, and China, the overall $\mathrm{M} / \mathrm{F}$ ratio of $\mathrm{CD}$ was approximately $2.0 .^{19,42-44}$ In Japan, the M/F ratio was 1.24 for UC and 2.40 for $\mathrm{CD} .{ }^{16}$ In Taiwan, the M/F ratio was 1.6 for UC and 2.2 for $\mathrm{CD} .{ }^{12}$ In two Indian studies, the $\mathrm{M} / \mathrm{F}$ ratios were 1.9 in 3,553 IBD patients, ${ }^{37}$ and 1.6 in 3,863 IBD patients. ${ }^{39}$ Therefore, $\mathrm{CD}$ showed a significant male predominance while UC showed a slight male predominance in Asia. In contrast, pooled analysis of 17 Western population-based cohorts showed a female predominance for $\mathrm{CD}$, with an $\mathrm{M} / \mathrm{F}$ ratio of $0.68-0.89$ after 25 years. ${ }^{45}$ In this analysis, no sex predominance was noted for UC until 45 years of age, but a slight male predominance with an M/F ratio of 1.15 to 1.47 was noted in patients aged 55 to 69 years. ${ }^{45}$

No explanation is currently available for the differences in the sex distributions between Asian and Western CD patients. The precise mechanism underlying these differences is unknown because previous observational studies were not designed to elucidate the etiology or mechanism. Furthermore, direct comparison of sex differences in previous Asian and Western studies is difficult, since the participants may have had different genotypic factors or environmental exposures, which are independently responsible for IBD development. As an example, smoking is more prevalent in men than in women in Asian countries, ${ }^{46}$ but this cannot fully explain the male predominance of $\mathrm{CD}$ in Asian countries. Therefore, further studies are needed to resolve the role of sex as a disease modifier for CD.

\section{AGE}

While the incidence of IBD in Western studies was characterized by a bimodal age distribution with peaks at 20 to 39 and 60 to 79 years, ${ }^{47-49}$ previous Asian studies showed a single peak without a bimodal age distribution. ${ }^{43,44,50}$ The appearance of a single peak in previous Asian studies may be attributable to either the small sample sizes (only 23 to 389 patients) with too few elderly patients ${ }^{43,44,50}$ or to the analysis of only the absolute number of patients rather than the age-specific incidence rate. A recent study from Korea, however, showed a bimodal age distribution, especially with UC patients aged 60 to 69 years. ${ }^{6}$ A Japanese study also showed a bimodal age distribution for UC with 40 to 44 years peak and 50 to 60 s peak. ${ }^{51}$ However, this study was limited by a survey-based small design $(n=343)$. In the ACCESS study, CD was associated with a bimodal age distribution, whereas the incidence of UC showed a single peak. ${ }^{4}$

In two Korean studies, ${ }^{6,19}$ the median age (22 to 24 years) at diagnosis of $\mathrm{CD}$ was lower than that of Western patients (27 to 31 years), ${ }^{52-54}$ but the median age (33 to 36 years) at diagnosis of UC was similar to that of Western patients ( 33 to 39 years). ${ }^{52-54}$ In Korea, the median age at 
diagnosis was lower for $\mathrm{CD}$ than for $\mathrm{UC}(\mathrm{p}<0.001)$, similar to the findings of a study published 10 years earlier from the same cohort. ${ }^{19}$ In Iran, the age at diagnosis for UC and CD patients was 31.4 and 27.9 years, respectively. ${ }^{38}$ In the analysis of Chinese studies, the mean age at diagnosis of pooled UC patients was 40.7 years. ${ }^{9}$ The ACCESS study reported that the median age at diagnosis of $\mathrm{UC}$ and $\mathrm{CD}$ patients was 43 and 33 years, respectively. ${ }^{5}$ Taken together, these findings suggest that the median age at diagnosis of $\mathrm{CD}$ is about 5 to 10 years earlier than that of UC in Asian countries, ${ }^{6,40}$ which is similar to the findings of Western studies. When compared to Korean studies, ${ }^{6,19}$ the median age at diagnosis of IBD was higher than that in the ACCESS study. ${ }^{4,5}$ Asian countries may show wide variations in the threshold for colonoscopy use, which is dependent on healthcare accessibility and may influence the median age at diagnosis of IBD. Because of the affordable colonoscopy access in South Korea, the median age at diagnosis of CD may be earlier than those in other studies.

\section{DISEASE EXTENT OF UC}

With respect to the disease extent of UC, more than half of the Asian IBD patients had proctitis (E1) at the time of diagnosis. ${ }^{6,9,19}$ In Korea, $54.3 \%$ of UC patients presented with $\mathrm{E} 1$ at diagnosis, while $22.5 \%$ and $23.2 \%$ showed leftsided colitis (E2) and extensive colitis (E3), respectively. ${ }^{6}$ The higher rate of $\mathrm{E} 1$ at diagnosis in the Korean study may be attributed to the broad use of endoscopic examination, which resulted in a higher detection rate of mild UC with E1. During 1986-2015, the proportion of E1 cases progressively increased, from $31.3 \%$ in $1986-1990$ to $62.1 \%$ in 2011-2015. In the data obtained 10 years earlier from the same cohort, $10 \%$ less (44\%) UC patients presented with E1. ${ }^{19}$ The ACCESS study reported E1, E2, and E3 in 37\%, $32 \%$, and $31 \%$ of the patients, respectively. ${ }^{4}$ The extension study of ACCESS also reported similar results, showing $\mathrm{E} 1$ in $32.6 \%$, E2 in $34.9 \%$ and $\mathrm{E} 3$ in $32.6 \%$ of the patients. ${ }^{5}$ In a single-hospital study from Hong Kong between 1990 to $2006,38.4 \%, 26.0 \%$, and $35.6 \%$ of the UC patients presented with E1, E2, and E3, respectively. The Australian patients in the ACCESS study showed similar disease extent of UC, with E1, E2, and E3 presenting in 32\%, 27\%, and $41 \%$ of the cases, respectively. ${ }^{4}$ In Western studies, $29 \%$ to $51 \%$ of UC patients presented with E1 at diagnosis. ${ }^{52,54-57}$ In general, there was no significant difference in the extent of UC between Asian and Western countries. However, the disease extent of UC should be interpreted with caution since it may be biased by study design.

When compared with population-based studies, hos- pital-based studies have an inherent referral bias because mild UC patients with E1 were less included in the hospital-based study. In a prospective registry from India, the proportions of UC cases with E1, E2, and E3 were 17.5\%, $58.6 \%$, and $23.9 \%$, respectively. ${ }^{39}$ One study in Thailand also showed a lower rate of E1 (21\%), and rates of $35 \%$ and $43 \%$ for E2 and E3, respectively. ${ }^{58}$ The lower rate of E1 in these studies ${ }^{39,58}$ may be explained by the hospital-based study design.

\section{DISEASE LOCATION OF CD}

In a Korean study, disease locations of $\mathrm{CD}$ were ileal (L1) in $24.9 \%$, colonic (L2) in $9.3 \%$ and ileocolonic (L3) in $65.8 \%$ of the cases. ${ }^{6}$ In this study, upper gastrointestinal disease modifier (L4) was present in $22.5 \%$ of the cases according to Montreal classification. The ACCESS study reported that the disease location of CD was L1, L2, L3, and $\mathrm{L} 4$ in $31.7 \%, 24.4 \%, 43.9 \%$, and $6.0 \%$ of the cases, respectively. ${ }^{5}$ In an IBD registry from India, L1, L2, L3, and $\mathrm{L} 4$ locations of $\mathrm{CD}$ were observed in $30.8 \%, 30.9 \%$, $36.3 \%$, and $2.1 \%$ of the cases, respectively. ${ }^{39}$ Interestingly, L3 was the most common ( $45 \%$ to $71 \%$ ) type of CD in East Asian studies, ${ }^{5,6,859,60}$ while L2 was the most common type (39\% to $52 \%$ ) in Western studies. ${ }^{56,61-64}$ In addition, a recent meta-analysis confirmed that the incidence of L4 in Asian CD patients was significantly higher than that in Caucasian CD patients ( $8 \%$ vs $4 \%$ ). ${ }^{65} \mathrm{~L} 4$ location is at risk for underestimation during work-up for the location of CD by skipping upper endoscopy or proximal small bowel imaging. The very high L4 proportion of $22.5 \%$ in Korea could be explained by affordability and easily accessibility of upper endoscopy or proximal small bowel imaging in Korea. ${ }^{6}$ Upper endoscopy is recommended only in CD patients with upper gastrointestinal symptoms in Western countries, ${ }^{66}$ however, routine upper endoscopy should be recommended to exactly classify the disease location of CD.

\section{DISEASE BEHAVIOR OF CD}

The behavior of $\mathrm{CD}$ may progress with time from an inflammatory (B1) to a stricturing (B2) or penetrating (B3) phenotype. In a Korean study, disease behaviors at CD diagnosis were B1, B2, and B3 in $81.1 \%, 8.1 \%$, and $10.8 \%$ of the cases, respectively. ${ }^{6}$ In this study, the proportion of B1 cases decreased from $78.9 \%$ in $1991-1995$ to $75.0 \%$ in 2011-2015, but the proportion of B3 cases increased from $10.5 \%$ in $1991-1995$ to $14.9 \%$ in $2011-2015 .{ }^{6}$ The ACCESS 
study reported B1, B2, and B3 phenotypes in $66 \%, 17 \%$, and $19 \%$ of the cases, respectively. ${ }^{4}$ The extension study of ACCESS cohort also reported B1, B2, and B3 phenotypes in $71.4 \%, 21.3 \%$, and $10.1 \%$ of the cases, respectively. ${ }^{5}$ In a Japanese single-center study including $520 \mathrm{CD}$ patients, stenosis or fistula were complicated in about half of patients after 5 years from diagnosis. ${ }^{67}$

In a population-based cohort from Olmsted County in the United States, $81 \%$ of patients had a B1 phenotype, followed by B2 and B3 phenotypes in $5 \%$ and $14 \%$ of the cases, respectively. ${ }^{68}$ In French CD patients $(\mathrm{n}=2,002)$ with disease duration $>5$ years, $60 \%$ of patients developed B2 or B3 complications. In this cohort, 20-year actuarial rates of $\mathrm{B} 1, \mathrm{~B} 2$, and $\mathrm{B} 3$ were $12 \%, 18 \%$, and $70 \%$, respectively. ${ }^{69}$ In a population-based cohort of elderly-onset $C D(n=367)$, $78 \%$ of patients had B1 behavior at diagnosis of $\mathrm{CD}$, but, digestive extension and complicated behavior occurred in $8 \%$ and $9 \%$, respectively. ${ }^{70}$ In 989 pediatric CD patients, the cumulative incidence of complicated disease was $13.0 \%$, $26.7 \%$, and $37.9 \%$ at 1,5 , and 10 years from the time of diagnosis of $\mathrm{CD} .^{71}$ The 10 -year cumulative incidences of $\mathrm{B} 2$ and B3 complications were $20.5 \%$ and $24.5 \%$, respectively.

In general, the disease behaviors of Asian $\mathrm{CD}$ patients were comparable to those of Western studies. ${ }^{6,68}$ However, a meta-analysis showed a more complicated behavior in Asian CD patients than Caucasian CD patients, with fewer cases of the B1 phenotype (61\% vs $69 \%$ ) and more cases of the B2 (21\% vs $17 \%)$ and B3 (14\% vs $13 \%)$ phenotypes. ${ }^{65}$ Further studies are required to evaluate this issue because of the lack of population-based studies with long-term follow-up from Asia. Perianal fistulas (PAFs) are very common in Asian CD patients. ${ }^{5,8,65,72}$ In a population-based study from Korea, PAF/abscess was present in $43.3 \%$ of the patients before or at diagnosis of $\mathrm{CD} .{ }^{6} \mathrm{In}$ a populationbased study from China, PAF was present in $58.5 \%$ of the newly diagnosed CD patients. ${ }^{8}$ A hospital-based study from Korea also reported PAF in $43.1 \%$ of the cases at diagnosis of $\mathrm{CD}{ }^{72}$ These findings were consistent with recent meta-analysis data indicating that PAF is more common in Asian CD patients than in Caucasian CD patients. ${ }^{65}$ Similarly, hospital-based Korean study reported that the cumulative occurrence rates of perianal lesions in $\mathrm{CD}$ were $37.2 \%$ at diagnosis, $45.2 \%$ and $53.0 \%$ after 5 years and 10 years, respectively. ${ }^{73}$ In contrast, a Western study reported that only $13 \%$ to $38 \%$ of CD patients had perianal disease. ${ }^{74}$ In addition, the ACCESS study, also reported that only $15.6 \%$ to $17.7 \%$ of the cases showed PAF at diagnosis of $\mathrm{CD} .{ }^{4,5}$ The frequency of perianal lesions in $\mathrm{CD}$ varies greatly depending on the definition, which may be a future research question for clear classification of $\mathrm{CD}$.
EXTRAINTESTINAL MANIFESTATION

In an Asian multinational study, extraintestinal manifestations (EIMs) were reported in $11.3 \%$ of IBD patients and noted in $8 \%$ of the patients before IBD diagnosis. ${ }^{75}$ In the ACCESS cohort, 19\% of Asian IBD patients had EIMs. ${ }^{76}$ In a Chinese study, $6.1 \%$ of pooled UC patients had EIMs. ${ }^{9}$ In an IBD registry from India, EIMs were recorded among $13 \%$ and $20 \%$ of the patients with UC and $\mathrm{CD}$, respectively. ${ }^{39}$ The prevalence of EIMs in the West was also variable, ranging between $6 \%$ and $47 \% .{ }^{77}$ The frequencies of EIMs in Asian countries have been lower than those in Western studies. ${ }^{39,44,75,76,78-80}$ However, the rate of EIM in IBD studies should be interpreted with caution because symptoms associated with EIM are transient and nonspecific and show a wide variety. Although primary sclerosing cholangitis (PSC) is the most reliable EIM, the prevalence of PSC is also variable because of differences in definition or diagnostic modalities. PSC was reported in $1.1 \%$ of UC and $0 \%$ of CD patients in a Korean study. ${ }^{81}$ PSC has also been reported in $2 \%$ to $8 \%$ of UC patients ${ }^{82,83}$ and $1 \%$ to $3 \%$ of CD patients ${ }^{84,85}$ in Western studies. Therefore, additional prospective studies are required on this issue.

\section{FAMILY AGGREGATION}

A positive family history of IBD was reported in $1.9 \%$ to $6.6 \%$ of the cases in Korean studies. ${ }^{86-88}$ In a hospital-based IBD registry from Korea, first- and second-degree family history of IBD was recorded in $2.4 \%$ of IBD patients, including $2.5 \%$ of CD patients and $2.4 \%$ of UC patients. ${ }^{86}$ In a single hospital-based study, a first-, second-, and/or third-degree family history of IBD was reported in $6.6 \%$ of the patients, including $6.8 \%$ of $\mathrm{CD}$ patients and $6.5 \%$ of UC patients. ${ }^{87}$ In a university and community hospital-based study, a first-degree family history of IBD was observed in $1.9 \%$ of IBD patients, including $1.5 \%$ of $\mathrm{CD}$ patients and $2.0 \%$ of UC patients. ${ }^{88}$ The crude prevalence of IBD in first-degree relatives of probands with IBD was $0.31 \%$. The lifetime risk of IBD was $0.54 \%$ in all first-degree relatives of IBD probands, $0.52 \%$ in UC probands, and $0.67 \%$ in CD probands, with overall lifetime relative risks of $0.12 \%$ in parents, $0.79 \%$ in siblings, and $1.43 \%$ in offspring. ${ }^{88}$

In a nationwide IBD registry from Japan, first-degree family history was reported in $2.5 \%$ of IBD patients, including $2.6 \%$ of CD patients and $2.7 \%$ of UC patients. ${ }^{89}$ In China, $1.5 \%$ of the pooled UC patients had a positive family history. ${ }^{9}$ In an IBD registry from India, family histories of IBD, UC, and CD were reported in $3.1 \%, 3.1 \%$, and $3.2 \%$ of the cases, respectively. ${ }^{39}$ In another study from India, 
first- and second-degree family histories of IBD, UC, and $\mathrm{CD}$ were reported in $4.25 \%, 4.34 \%$, and $4.13 \%$ of the cases, respectively. ${ }^{37}$ In a nationwide IBD registry from Iran, $11.8 \%$ of the participants showed positive results for firstdegree family history and $6.87 \%$ showed positive results for second-degree family history. ${ }^{38}$ In general, IBD patients in the Middle East had a higher rate of family history compared to those in East Asia. Considering the 5\% to 18\% incidence of positive family histories in the Western countries, ${ }^{89,90}$ Asian IBD patients showed a much lower frequency of family history. Nevertheless, the population relative risk in the Korean study was $13.8,{ }^{86}$ which is comparable to the risk reported in Western studies, ${ }^{91,92}$ which means that the positive family history in Korea may become similar to those in Western countries as the prevalence of IBD approaches that in Western countries. ${ }^{46}$ Therefore, the low rate of familial aggregation in Asian IBD patients may be explained by the presently lower prevalence of IBD in Asia than in the West. ${ }^{46}$ The data for familial aggregation may be variable because of different definitions of familial aggregation ranging from a first-degree to first-third-degree family history in previous studies. ${ }^{86-88}$ In addition, a positive family history in IBD patients may have been underestimated in observational studies due to incomplete historytaking.

\section{CONCLUSION}

Asian IBD patients may show different epidemiologic characteristics with real heterogeneity of phenotypes in comparison with Western IBD patients. Table 1 summarizes the different phenotypes of IBD in the Asian and Western populations. However, the findings of Asian studies may be biased due to delays in diagnosis by lack of medical awareness and insufficient medical logistics. Even within Asia, there were some differences in the epidemiologic characteristics of IBD, especially between East Asia and the Middle East. Thus, more rigorous studies are needed to identify the epidemiologic differences within Asia considering the impact of both genetic and environmental factors between Asian countries.

\section{CONFLICTS OF INTEREST}

No potential conflict of interest relevant to this article was reported.
ORCID

Su Bee Park https://orcid.org/0000-0002-4638-413X Jin Young Yoon https://orcid.org/0000-0002-5280-0443 Jae Myung Cha https://orcid.org/0000-0001-9403-230X

\section{SUPPLEMENTARY MATERIALS}

Supplementary materials can be accessed at https://doi. org/10.5009/gnl210385.

\section{REFERENCES}

1. Kaplan GG, Windsor JW. The four epidemiological stages in the global evolution of inflammatory bowel disease. Nat Rev Gastroenterol Hepatol 2021;18:56-66.

2. Molodecky NA, Soon IS, Rabi DM, et al. Increasing incidence and prevalence of the inflammatory bowel diseases with time, based on systematic review. Gastroenterology 2012;142:46-54.

3. Kaplan GG. The global burden of IBD: from 2015 to 2025. Nat Rev Gastroenterol Hepatol 2015;12:720-727.

4. Ng SC, Tang W, Ching JY, et al. Incidence and phenotype of inflammatory bowel disease based on results from the AsiaPacific Crohn's and Colitis Epidemiology Study. Gastroenterology 2013;145:158-165.

5. Ng SC, Kaplan GG, Tang W, et al. Population density and risk of inflammatory bowel disease: a prospective population-based study in 13 countries or regions in Asia-pacific. Am J Gastroenterol 2019;114:107-115.

6. Park SH, Kim YJ, Rhee KH, et al. A 30-year trend analysis in the epidemiology of inflammatory bowel disease in the Songpa-Kangdong District of Seoul, Korea in 1986-2015. J Crohns Colitis 2019;13:1410-1417.

7. Zhao J, Ng SC, Lei Y, et al. First prospective, populationbased inflammatory bowel disease incidence study in mainland of China: the emergence of "western" disease. Inflamm Bowel Dis 2013;19:1839-1845.

8. Zeng Z, Zhu Z, Yang Y, et al. Incidence and clinical characteristics of inflammatory bowel disease in a developed region of Guangdong Province, China: a prospective populationbased study. J Gastroenterol Hepatol 2013;28:1148-1153.

9. Jiang XL, Cui HF. An analysis of 10218 ulcerative colitis cases in China. World J Gastroenterol 2002;8:158-161.

10. Wei SC, Lin MH, Tung CC, et al. A nationwide populationbased study of the inflammatory bowel diseases between 1998 and 2008 in Taiwan. BMC Gastroenterol 2013;13:166.

11. Chuang CH, Lin SH, Chen CY, Sheu BS, Kao AW, Wang JD. Increasing incidence and lifetime risk of inflammatory bowel 
disease in Taiwan: a nationwide study in a low-endemic area 1998-2010. Inflamm Bowel Dis 2013;19:2815-2819.

12. Yen HH, Weng MT, Tung CC, et al. Epidemiological trend in inflammatory bowel disease in Taiwan from 2001 to 2015: a nationwide populationbased study. Intest Res 2019;17:54-62.

13. Abdul-Baki H, ElHajj I, El-Zahabi LM, et al. Clinical epidemiology of inflammatory bowel disease in Lebanon. Inflamm Bowel Dis 2007;13:475-480.

14. Al-Shamali MA, Kalaoui M, Patty I, Hasan F, Khajah A, AlNakib B. Ulcerative colitis in Kuwait: a review of 90 cases. Digestion 2003;67:218-224.

15. Niv Y, Abuksis G, Fraser GM. Epidemiology of ulcerative colitis in Israel: a survey of Israeli kibbutz settlements. Am J Gastroenterol 2000;95:693-698.

16. Murakami Y, Nishiwaki Y, Oba MS, et al. Estimated prevalence of ulcerative colitis and Crohn's disease in Japan in 2014: an analysis of a nationwide survey. J Gastroenterol 2019;54:1070-1077.

17. Kaibullayeva J, Ualiyeva A, Oshibayeva A, Dushpanova A, Marshall JK. Prevalence and patient awareness of inflammatory bowel disease in Kazakhstan: a cross-sectional study. Intest Res 2020;18:430-437.

18. Tezel A, Dökmeci G, Eskiocak M, Umit H, Soylu AR. Epidemiological features of ulcerative colitis in Trakya, Turkey. J Int Med Res 2003;31:141-148.

19. Yang SK, Yun S, Kim JH, et al. Epidemiology of inflammatory bowel disease in the Songpa-Kangdong district, Seoul, Korea, 1986-2005: a KASID study. Inflamm Bowel Dis 2008; 14:542-549.

20. Thia KT, Loftus EV Jr, Sandborn WJ, Yang SK. An update on the epidemiology of inflammatory bowel disease in Asia. Am J Gastroenterol 2008;103:3167-3182.

21. Thia KT, Luman W, Jin OC. Crohn's disease runs a more aggressive course in young Asian patients. Inflamm Bowel Dis 2006;12:57-61.

22. Lok KH, Hung HG, $\mathrm{Ng} \mathrm{CH}$, et al. Epidemiology and clinical characteristics of ulcerative colitis in Chinese population: experience from a single center in Hong Kong. J Gastroenterol Hepatol 2008;23:406-410.

23. Kaplan GG, Ng SC. Understanding and preventing the global increase of inflammatory bowel disease. Gastroenterology 2017;152:313-321.

24. Ng SC, Tang W, Leong RW, et al. Environmental risk factors in inflammatory bowel disease: a population-based casecontrol study in Asia-Pacific. Gut 2015;64:1063-1071.

25. Xu L, Lochhead P, Ko Y, Claggett B, Leong RW, Ananthakrishnan AN. Systematic review with meta-analysis: breastfeeding and the risk of Crohn's disease and ulcerative colitis. Aliment Pharmacol Ther 2017;46:780-789.

26. Wang Q, Xu KQ, Qin XR, Wen-Lu, Yan-Liu, Wang XY. Association between physical activity and inflammatory bowel disease risk: a meta-analysis. Dig Liver Dis 2016;48:14251431.

27. Ng WK, Wong SH, Ng SC. Changing epidemiological trends of inflammatory bowel disease in Asia. Intest Res 2016;14:111-119.

28. Kondo K, Ohfuji S, Watanabe K, et al. The association between environmental factors and the development of Crohn's disease with focusing on passive smoking: a multicenter case-control study in Japan. PLoS One 2019;14:e0216429.

29. Jang JY, Kim HJ, Jung JH, et al. The role of smoking as a risk factor in inflammatory bowel diseases: single center study in Korea. Korean J Gastroenterol 2006;47:198-204.

30. Naganuma M, Iizuka B, Torii A, et al. Appendectomy protects against the development of ulcerative colitis and reduces its recurrence: results of a multicenter case-controlled study in Japan. Am J Gastroenterol 2001;96:1123-1126.

31. Jiang L, Xia B, Li J, et al. Risk factors for ulcerative colitis in a Chinese population: an age-matched and sex-matched casecontrol study. J Clin Gastroenterol 2007;41:280-284.

32. Firouzi F, Bahari A, Aghazadeh R, Zali MR. Appendectomy, tonsillectomy, and risk of inflammatory bowel disease: a case control study in Iran. Int J Colorectal Dis 2006;21:155-159.

33. Mak WY, Zhao M, Ng SC, Burisch J. The epidemiology of inflammatory bowel disease: East meets West. J Gastroenterol Hepatol 2020;35:380-389.

34. Hou JK, Abraham B, El-Serag H. Dietary intake and risk of developing inflammatory bowel disease: a systematic review of the literature. Am J Gastroenterol 2011;106:563-573.

35. Shoda R, Matsueda K, Yamato S, Umeda N. Epidemiologic analysis of Crohn disease in Japan: increased dietary intake of $n-6$ polyunsaturated fatty acids and animal protein relates to the increased incidence of Crohn disease in Japan. Am J Clin Nutr 1996;63:741-745.

36. Sakamoto N, Kono S, Wakai K, et al. Dietary risk factors for inflammatory bowel disease: a multicenter case-control study in Japan. Inflamm Bowel Dis 2005;11:154-163.

37. Banerjee R, Pal P, Hutfless S, Ganesh BG, Reddy DN. Familial aggregation of inflammatory bowel disease in India: prevalence, risks and impact on disease behavior. Intest Res 2019;17:486-495.

38. Malekzadeh MM, Sima A, Alatab S, et al. Iranian Registry of Crohn's and Colitis: study profile of first nation-wide inflammatory bowel disease registry in Middle East. Intest Res 2019;17:330-339.

39. Sood A, Kaur K, Mahajan R, et al. Colitis and Crohn's Foundation (India): a first nationwide inflammatory bowel disease registry. Intest Res 2021;19:206-216.

40. Kedia S, Ahuja V. Epidemiology of inflammatory bowel disease in India: the great shift East. Inflamm Intest Dis 2017;2:102-115.

41. Shah SC, Khalili H, Chen CY, et al. Sex-based differences in 
the incidence of inflammatory bowel diseases-pooled analysis of population-based studies from the Asia-Pacific region. Aliment Pharmacol Ther 2019;49:904-911.

42. Morita N, Toki S, Hirohashi T, et al. Incidence and prevalence of inflammatory bowel disease in Japan: nationwide epidemiological survey during the year 1991. J Gastroenterol 1995;30 Suppl 8:1-4.

43. Leong RW, Lau JY, Sung JJ. The epidemiology and phenotype of Crohn's disease in the Chinese population. Inflamm Bowel Dis 2004;10:646-651.

44. Jiang L, Xia B, Li J, et al. Retrospective survey of 452 patients with inflammatory bowel disease in Wuhan city, central China. Inflamm Bowel Dis 2006;12:212-217.

45. Shah SC, Khalili H, Gower-Rousseau C, et al. Sex-based differences in incidence of inflammatory bowel diseases-pooled analysis of population-based studies from western countries. Gastroenterology 2018;155:1079-1089.

46. Yang SK. How does the epidemiology of inflammatory bowel disease differ between East and West? A Korean perspective. Inflamm Intest Dis 2017;2:95-101.

47. Benchimol EI, Manuel DG, Guttmann A, et al. Changing age demographics of inflammatory bowel disease in Ontario, Canada: a population-based cohort study of epidemiology trends. Inflamm Bowel Dis 2014;20:1761-1769.

48. Lapidus A, Bernell O, Hellers G, Persson PG, Löfberg R. Incidence of Crohn's disease in Stockholm County 1955-1989. Gut 1997;41:480-486.

49. Jeuring SF, van den Heuvel TR, Zeegers MP, et al. Epidemiology and long-term outcome of inflammatory bowel disease diagnosed at elderly age-an increasing distinct entity? Inflamm Bowel Dis 2016;22:1425-1434.

50. Sood A, Midha V, Sood N, Bhatia AS, Avasthi G. Incidence and prevalence of ulcerative colitis in Punjab, North India. Gut 2003;52:1587-1590.

51. Takahashi H, Matsui T, Hisabe T, et al. Second peak in the distribution of age at onset of ulcerative colitis in relation to smoking cessation. J Gastroenterol Hepatol 2014;29:16031608

52. Ekbom A, Helmick C, Zack M, Adami HO. The epidemiology of inflammatory bowel disease: a large, population-based study in Sweden. Gastroenterology 1991;100:350-358.

53. Loftus CG, Loftus EV Jr, Harmsen WS, et al. Update on the incidence and prevalence of Crohn's disease and ulcerative colitis in Olmsted County, Minnesota, 1940-2000. Inflamm Bowel Dis 2007;13:254-261.

54. Vind I, Riis L, Jess T, et al. Increasing incidences of inflammatory bowel disease and decreasing surgery rates in Copenhagen City and County, 2003-2005: a population-based study from the Danish Crohn colitis database. Am J Gastroenterol 2006;101:1274-1282.

55. Moum B, Vatn MH, Ekbom A, et al. Incidence of ulcerative colitis and indeterminate colitis in four counties of southeastern Norway, 1990-93: a prospective population-based study. The Inflammatory Bowel South-Eastern Norway (IBSEN) Study Group of Gastroenterologists. Scand J Gastroenterol 1996;31:362-366.

56. Samuel S, Ingle SB, Dhillon S, et al. Cumulative incidence and risk factors for hospitalization and surgery in a population-based cohort of ulcerative colitis. Inflamm Bowel Dis 2013;19:1858-1866.

57. Jacobsen BA, Fallingborg J, Rasmussen $\mathrm{HH}$, et al. Increase in incidence and prevalence of inflammatory bowel disease in northern Denmark: a population-based study, 1978-2002. Eur J Gastroenterol Hepatol 2006;18:601-606.

58. Aniwan S, Limsrivilai J, Pongprasobchai S, et al. Temporal trend in the natural history of ulcerative colitis in a country with a low incidence of ulcerative colitis from 2000 through 2018. Intest Res 2021;19:186-193.

59. Chow DK, Leong RW, Lai LH, et al. Changes in Crohn's disease phenotype over time in the Chinese population: validation of the Montreal classification system. Inflamm Bowel Dis 2008;14:536-541.

60. Oriuchi T, Hiwatashi N, Kinouchi Y, et al. Clinical course and longterm prognosis of Japanese patients with Crohn's disease: predictive factors, rates of operation, and mortality. J Gastroenterol 2003;38:942-953.

61. Yapp TR, Stenson R, Thomas GA, Lawrie BW, Williams GT, Hawthorne AB. Crohn's disease incidence in Cardiff from 1930: an update for 1991-1995. Eur J Gastroenterol Hepatol 2000;12:907-911.

62. Moum B, Vatn MH, Ekbom A, et al. Incidence of Crohn's disease in four counties in southeastern Norway, 1990-93: a prospective population-based study. The Inflammatory Bowel South-Eastern Norway (IBSEN) Study Group of Gastroenterologists. Scand J Gastroenterol 1996;31:355-361.

63. Sjöberg D, Holmström T, Larsson M, et al. Incidence and clinical course of Crohn's disease during the first year: results from the IBD Cohort of the Uppsala Region (ICURE) of Sweden 2005-2009. J Crohns Colitis 2014;8:215-222.

64. Lapidus A. Crohn's disease in Stockholm County during 1990-2001: an epidemiological update. World J Gastroenterol 2006;12:75-81.

65. Shi HY, Levy AN, Trivedi HD, Chan F, Ng SC, Ananthakrishnan AN. Ethnicity influences phenotype and outcomes in inflammatory bowel disease: a systematic review and meta-analysis of population-based studies. Clin Gastroenterol Hepatol 2018;16:190-197.

66. Annunziata ML, Caviglia R, Papparella LG, Cicala M. Upper gastrointestinal involvement of Crohn's disease: a prospective study on the role of upper endoscopy in the diagnostic work-up. Dig Dis Sci 2012;57:1618-1623.

67. Sato Y, Matsui T, Yano Y, et al. Long-term course of Crohn's 
disease in Japan: incidence of complications, cumulative rate of initial surgery, and risk factors at diagnosis for initial surgery. J Gastroenterol Hepatol 2015;30:1713-1719.

68. Thia KT, Sandborn WJ, Harmsen WS, Zinsmeister AR, Loftus EV Jr. Risk factors associated with progression to intestinal complications of Crohn's disease in a population-based cohort. Gastroenterology 2010;139:1147-1155.

69. Cosnes J, Cattan S, Blain A, et al. Long-term evolution of disease behavior of Crohn's disease. Inflamm Bowel Dis 2002;8:244-250.

70. Charpentier C, Salleron J, Savoye G, et al. Natural history of elderly-onset inflammatory bowel disease: a populationbased cohort study. Gut 2014;63:423-432.

71. Gupta N, Bostrom AG, Kirschner BS, et al. Incidence of stricturing and penetrating complications of Crohn's disease diagnosed in pediatric patients. Inflamm Bowel Dis 2010;16:638-644.

72. Park SH, Yang SK, Park SK, et al. Long-term prognosis of Crohn's disease and its temporal change between 1981 and 2012: a hospital-based cohort study from Korea. Inflamm Bowel Dis 2014;20:488-494.

73. Yoon JY, Cheon JH, Park SJ, Kim TI, Kim WH. Effects of perianal involvement on clinical outcomes in Crohn's disease over 10 years. Gut Liver 2018;12:297-305.

74. American Gastroenterological Association Clinical Practice Committee. American Gastroenterological Association medical position statement: perianal Crohn's disease. Gastroenterology 2003;125:1503-1507.

75. Park SK, Wong Z, Park SH, et al. Extraintestinal manifestation of inflammatory bowel disease in Asian patients: a multinational study. Dig Liver Dis 2021;53:196-201.

76. Ng SC, Zeng Z, Niewiadomski O, et al. Early course of inflammatory bowel disease in a population-based inception cohort study from 8 countries in Asia and Australia. Gastroenterology 2016;150:86-95.

77. Vavricka SR, Schoepfer A, Scharl M, Lakatos PL, Navarini A, Rogler G. Extraintestinal manifestations of inflammatory bowel disease. Inflamm Bowel Dis 2015;21:1982-1992.

78. Wang Y, Ouyang Q; APDW 2004 Chinese IBD working group. Ulcerative colitis in China: retrospective analysis of 3100 hospitalized patients. J Gastroenterol Hepatol 2007;22:1450-1455.

79. Ling KL, Ooi CJ, Luman W, Cheong WK, Choen FS, Ng HS. Clinical characteristics of ulcerative colitis in Singapore, a multiracial city-state. J Clin Gastroenterol 2002;35:144-148.
80. Monsén U, Sorstad J, Hellers G, Johansson C. Extracolonic diagnoses in ulcerative colitis: an epidemiological study. Am J Gastroenterol 1990;85:711-716.

81. Ye BD, Yang SK, Boo SJ, et al. Clinical characteristics of ulcerative colitis associated with primary sclerosing cholangitis in Korea. Inflamm Bowel Dis 2011;17:1901-1906.

82. Broomé U, Glaumann H, Hellers G, Nilsson B, Sörstad J, Hultcrantz R. Liver disease in ulcerative colitis: an epidemiological and follow up study in the county of Stockholm. Gut 1994;35:84-89.

83. Heikius B, Niemelä S, Lehtola J, Karttunen T, Lähde S. Hepatobiliary and coexisting pancreatic duct abnormalities in patients with inflammatory bowel disease. Scand J Gastroenterol 1997;32:153-161.

84. Vavricka SR, Brun L, Ballabeni P, et al. Frequency and risk factors for extraintestinal manifestations in the Swiss inflammatory bowel disease cohort. Am J Gastroenterol 2011;106:110-119.

85. Rasmussen HH, Fallingborg JF, Mortensen PB, Vyberg M, Tage-Jensen U, Rasmussen SN. Hepatobiliary dysfunction and primary sclerosing cholangitis in patients with Crohn's disease. Scand J Gastroenterol 1997;32:604-610.

86. Chung SH, Park SJ, Lee HS, et al. Similar clinical characteristics of familial and sporadic inflammatory bowel disease in South Korea. World J Gastroenterol 2014;20:17120-17126.

87. Hwang SW, Kwak MS, Kim WS, et al. Influence of a positive family history on the clinical course of inflammatory bowel disease. J Crohns Colitis 2016;10:1024-1032.

88. Park JB, Yang SK, Byeon JS, et al. Familial occurrence of inflammatory bowel disease in Korea. Inflamm Bowel Dis 2006;12:1146-1151.

89. Kuwahara E, Asakura K, Nishiwaki Y, et al. Effects of family history on inflammatory bowel disease characteristics in Japanese patients. J Gastroenterol 2012;47:961-968.

90. Yang H, McElree C, Roth MP, Shanahan F, Targan SR, Rotter JI. Familial empirical risks for inflammatory bowel disease: differences between Jews and non-Jews. Gut 1993;34:517524.

91. Peeters M, Nevens H, Baert F, et al. Familial aggregation in Crohn's disease: increased age-adjusted risk and concordance in clinical characteristics. Gastroenterology 1996;111:597-603.

92. Orholm M, Munkholm P, Langholz E, Nielsen OH, Sørensen TI, Binder V. Familial occurrence of inflammatory bowel disease. N Engl J Med 1991;324:84-88. 